\title{
Temperature control of robotic friction stir welding using the thermoelectric effect
}

\author{
Jeroen De Backer • Gunnar Bolmsjö • \\ Anna-Karin Christiansson
}

Received: 26 March 2013 / Accepted: 27 August 2013 /Published online: 14 September 2013

(C) The Author(s) 2013. This article is published with open access at Springerlink.com

\begin{abstract}
Friction stir welding (FSW) of non-linear joints receives an increasing interest from several industrial sectors like automotive, urban transport and aerospace. A forcecontrolled robot is particularly suitable for welding complex geometries in lightweight alloys. However, complex geometries including three-dimensional joints, non-constant thicknesses and heat sinks such as clamps cause varying heat dissipation in the welded product. This will lead to changes in the process temperature and hence an unstable FSW process with varying mechanical properties. Furthermore, overheating can lead to a meltdown, causing the tool to sink down into the workpiece. This paper describes a temperature controller that modifies the spindle speed to maintain a constant welding temperature. A newly developed temperature measurement method is used which is able to measure the average tool temperature without the need for thermocouples inside the tool. The method is used to control both the plunging and welding operation. The developments presented here are applied to a robotic FSW system and can be directly implemented in a production setting.
\end{abstract}

Keywords Frictionstirwelding · FSW · Temperature control · Force control $\cdot$ Robotics $\cdot$ Process automation

\section{Introduction}

Friction stir welding (FSW) is a solid-state joining process, particularly suitable for joining metals with low melting point like aluminium. The process uses a non-consumable rotating tool which is pushed into the material under high pressure.

J. De Backer $(\varangle) \cdot$ G. Bolmsjö • A.-K. Christiansson

Department of Engineering Science, University West, Trollhättan,

Sweden

e-mail: jeroen.debacker@hv.se
The combination of plastic deformation and friction generates the required heat to soften the material. The tool mechanically stirs the softened material, creating a high-quality welding joint. The heat input into the material and the resulting welding temperature can be controlled by adapting process parameters like the down-force, rotational speed or welding speed as shown in Fig. 1.

Since the introduction of FSW in the early 1990s [1], the major part of FSW applications consists of straight joints, performed by linear FSW machines or milling machines. Initially, the process was only suitable for lightweight alloys, but recent developments in tool materials make FSW of steel [2] and nickel alloys [3] feasible. The obtained mechanical properties with FSW are superior to most fusion welding processes. The absence of filler material and shielding gas, and the low energy input result in low operating costs for FSW of lightweight alloys like aluminium. For steel, however, the high wear of the tools still makes FSW significantly more expensive than fusion welding [4].

The automation of the friction stir welding (FSW) process and the online control of parameters is still a relatively small part of the research in the area of FSW. However, several researchers have demonstrated the necessity to control parameters during welding to maintain a stable process. If the welding operation is performed by an industrial robot with serial kinematics, there arise significant deflections in the robot joints due to the high forces. This can cause the tool to deviate several millimetres from the programmed joint line [5]. To overcome the deviation problem in axial direction, down-force control is recommended for a stable pressure of the tool on the welding material [6-8]. Even the stiff parallelkinematics robots benefit from force-controlled FSW $[9,10]$. Longhurst et al. presented an alternative to force control [11], where the tool torque is measured and kept constant by adapting the $z$-position of the tool. This approach shows good results, but it is not discussed how the system behaves for 


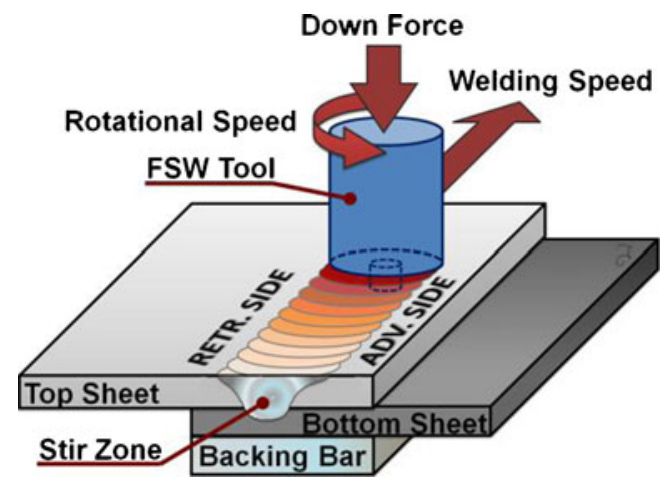

Fig. 1 Principle drawing of the FSW process for overlap joints with indication of the main parameters

tools with a diameter smaller than the used $18 \mathrm{~mm}$. The torque for smaller tools is much lower, and thus the torque changes will be accordingly smaller. Davis recently developed a fuzzy logic controller using the power input into the material as control variable. This approach is based on previous research which demonstrated a relation between the power and the spindle speed and down-force [12].

This paper describes a force- and temperature-controlled robot system for FSW. Temperature control is particularly important for FSW of complex geometries with varying heat dissipation. Several factors can influence the welding temperature and accordingly the weld quality: workpiece geometry and thickness, preheating, environment temperature, backing material, clamping, tool wear, etc. The force-controlled robot performs the FSW operation with a constant axial force by adaptation of the robot's axial position. Because the material hardness is temperature-dependent, a higher welding temperature will result in a softer workpiece. At a certain "critical" temperature, the material becomes too soft and collapses under the pressure of the tool. This effect is referred to as "meltdown", although the material collapses before the actual melting temperature is reached. A meltdown leads to a severe welding defect and possible tool or fixture damage. Especially in heattreatable alloys with high yield strength (e.g. the used AA 6082-T6), there is a steep decrease in the strength with increasing temperature. This makes welding of these alloys in forcecontrolled mode more challenging than non-heat-treatable alloys.

There are still relatively few physical models that are able to provide an accurate temperature profile under the FSW tool. The available physical models have different initial conditions. The early models assumed "sliding conditions", where no workpiece material sticks to the tool during rotation [13]. Later models did consider this effect, the so-called sticking conditions [14]. The main problem is the estimation of the friction coefficient between the tool and the workpiece. This makes it hard to predict absolute temperatures. Therefore, the model is usually mapped with measurements in a known location during welding. The models cannot account for unexpected disturbances in the process, which highlights the relevance of closed-loop temperature control.

The Swedish nuclear fuel and waste management company (SKB) has successfully implemented a cascade temperature controller for welding 50-mm-thick copper canisters which are planned to contain and seal nuclear waste. Thermocouples inside the welding tool are used for temperature measurement. Temperature and torque are controlled by changing the spindle speed [15]. The thick copper and slow welding speed is associated with high time constants in both cascade loops. This controller cannot be transferred directly to applications in thin aluminium where the time constants are much smaller and the torque is much lower. Smith and Schroeder presented an approach for temperature control in robotic friction stir processing [16]. The temperature measurements were fed back to a proportional-integral-derivative (PID) controller, which modified the axial force of the robot. A temperature controller for thin materials was also demonstrated by Fehrenbacher et al. [17]. The thermocouples used to measure the temperature were inserted in the tool, close to the shoulder surface, and were able to measure temperature changes every $30^{\circ}$ of tool rotation. Although the method is very accurate, it requires small holes, drilled in the tool, and the thermocouples have to be inserted manually in every tool. This makes the method less suitable for automated production.

The friction stir welding process is usually described in four steps: plunging, dwelling, welding and retracting. During plunging, the actuator performs a downward movement along the tool axis, pressing the tool probe into the material. Once the shoulder is in contact, there is a certain wait time to reach the desired temperature (dwelling). Then the actuator starts the forward movement along the joint line. As highlighted in the work by Soron [7], the transition from the downward movement during plunging to forward welding movement is difficult on machines with high compliance such as industrial robots. Several approaches were investigated, each with their drawback: the spindle motor torque can detect an increase in torque when the shoulder comes in contact with the material. For small welding tools, however, this torque peak is small and hard to detect. Another approach is the virtual plunge depth, corresponding to the pin length plus the expected deflection of the robot. This is, however, highly depending on the location and orientation of the welding tool. A third approach is by monitoring the robot's linear speed during plunging. This speed will decrease as the tool shoulder comes in contact with the material, but for small-diameter tools, this dip in speed is hard to detect. The use of temperature feedback, as described in this paper, makes the plunge operation independent from the type of machine and the location of the weld in the robot's workspace.

This paper presents the control of the plunge operation and the welding temperature in robotic FSW by using a novel temperature measurement method for FSW, suitable for 
automated production. This patent-pending method is based on the thermoelectric effect between the tool and the workpiece and makes the use of additional sensors inside the tool or workpiece obsolete. Welds on complex geometries are compared with and without controller, and it is shown that the controller makes it possible to weld geometries which otherwise could not be welded. The controller makes the robotic FSW process more robust and thus more suitable in industrial settings.

\section{System architecture}

The research on temperature control of FSW as described in this paper makes use of the existing FSW robot facilities at the Production Technology Centre in Trollhättan, Sweden. The robot system is described in Section 2.1. The system is complemented with a measurement PC, a temperature measurement system (Section 2.2) and a newly developed temperature controller (Section 2.3). The controller communicates with the robot system through a Profibus DP network.

\subsection{Robot system}

All the welding tests in this study were performed on an ESAB Rosio FSW robot system, which is based on an ABB IRB-7600 with 500-kg payload. The FSW robot has an embedded force sensor for direct force control (Fig. 2). The robot can deliver a maximum force of $15 \mathrm{kN}$ in a limited area of the workspace. The robot features and the force control strategy are further discussed in [7]. The FSW tool rotation is driven by an electric servo motor which can deliver up to a $45-\mathrm{Nm}$ torque and at 4,500 rpm. With the current gearbox configuration, the maximal spindle speed is limited to $1,800 \mathrm{rpm}$. The servo drive has a Profibus DP (slave) interface which gives access to the servo parameters. The robot controller has a Profibus DP Master interface for communication with the servo drive and the measurement PC.

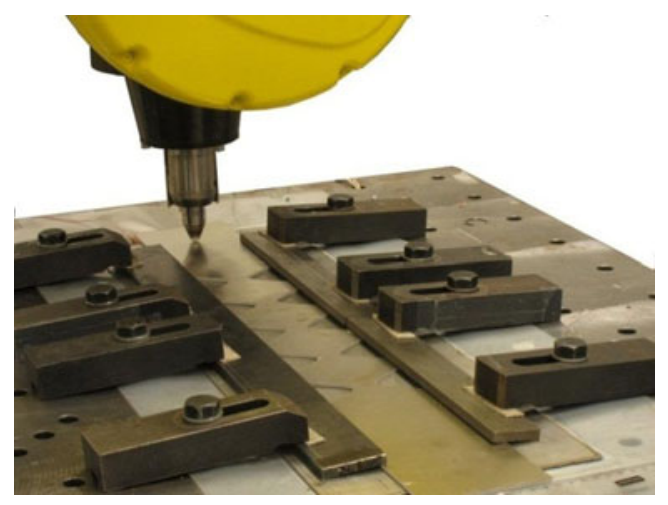

Fig. 2 The FSW robot with the welding setup

\subsection{Data acquisition and measurement system}

The complete control scheme for the used FSW robot system is shown in Fig. 3. The existing robot system contains the standard $\mathrm{ABB}$ robot (orange), force control (blue) and the spindle (purple). This is complemented with the temperature control system (red). The communication between individual components can be analogue (red arrow), Profibus (green arrow) or internal signals (black arrow).

The force control is handled internally by the ABB robot controller. The desired force can be set in the robot program or on the teach pendent, using the ESAB Rosio human-machine interface. The force data can be read by the measurement PC through the Profibus DP communication network. Outside the robot system, the force data is only used for data logging.

The temperature is measured from the thermoelectric signal between the tool and the workpiece. This tool-workpiece thermocouple (TWT) method provides accurate measurements of the tool temperature under the tool shoulder, close to edge of the tool [18]. The principle is explained by means of Fig. 4: The hot welding interface $(\mathrm{A})$ is a connection between the steel welding tool and the aluminium workpiece. The different thermoelectric properties in both materials will induce different thermoelectric potentials between the cold junctions in the tool and the workpiece ( $\mathrm{B}$ and $\mathrm{C}$, respectively). The induced voltage difference at the cold junctions is related to the welding temperature by the thermoelectric coefficient. This coefficient is identified during calibration of the TWT, by heating the tool-workpiece interface and measuring the ratio of the voltage (D) and the corresponding temperature difference. The temperature in (A) can be found by other measurement devices such as a thermocouple.

To prove the accuracy of the TWT method, the measurements are compared with type $\mathrm{K}$ thermocouples, connected to a National Instruments (NI) 9213 thermocouple input module with 16 channels. Temperature can be measured at $75 \mathrm{~Hz}$ per channel. The temperature measurements are transferred via USB 2.0 to the NI LabVIEW software on the measurement PC. This software combines a graphical user interface (GUI) with a drag-and-drop-type programming

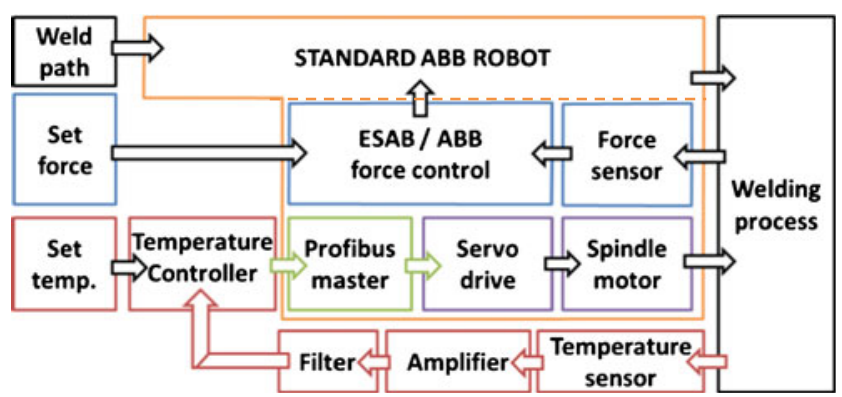

Fig. 3 Control scheme for the ESAB Rosio system. The red boxes involve the newly developed temperature control 


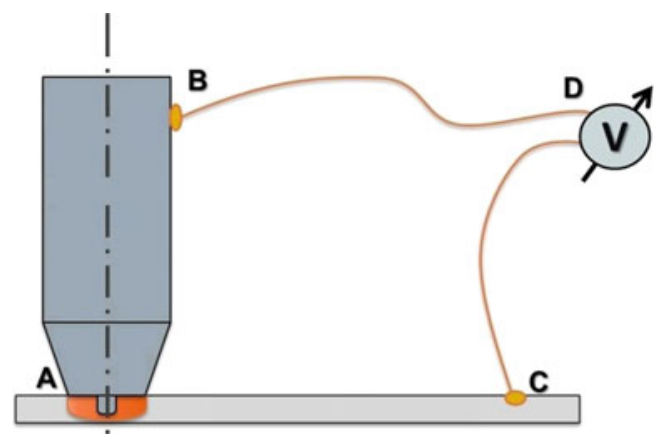

Fig. 4 Setup for calibration of the temperature measurement method

language. The temperature controller box, shown in Fig. 3, includes the following:

- GUI for changing control parameters and for supervision of the $\mathrm{I} / \mathrm{O}$ signals; temperature and spindle speed

- Software PID controller, generating a set value for the spindle speed, based on the temperature error

- Profibus slave which sends the desired spindle speed to the robot control system and reads the current spindle speed

\subsection{Control structure}

The selection of control parameter was based on an earlier research [15] where a Box-Behnken response surface experiment was performed, and the rotational speed was shown to be the most influencing parameter. This study was for FSW of 50-mm-thick copper on a custom-built machine. A major difference between typical FSW machines and the robotic approach is the possibility to measure and control the axial force online. The risk of meltdown is not present in the rigid position-controlled machines because the machine deflections are negligible. Another difference is related to material thickness and tool dimension where workpieces in rigid machines in general have a uniform shape, while robotic FSW provides for great variation in such properties. For tools with a largediameter shoulder, there are major variations in spindle torque with varying temperature [15], due to the large contact area between the tool and workpiece. This is obviously much smaller for the small-diameter tools, and torque is therefore less suitable as control parameter.

In general, the choice for a robot to perform FSW is related to more complex geometries such as $2 \mathrm{D}$ and $3 \mathrm{D}$ joints, which are usually more difficult to weld than straight joints. The temperature measurement method used in this paper can provide experimental knowledge on the tool temperature during plunging and hence improve the initiation phase of robotic FSW. The tool temperature and the plunge time for different parameter settings was measured and analysed. For the actual controller development, the step response was analysed, corresponding to a disturbance during the steady-state welding operation. From the step responses, a first-order process approximation was calculated and used for determining a first set of control parameters.

A typical PI controller is chosen for control. The $\mathrm{D}$-action is not included for two reasons: first, the welding process can be considered "slow", and second, the temperature measurements are subject to noise, which could cause instability of the controller.

Since a first-order model and PI control have shown to improve the process behaviour significantly, this paper leaves more advanced models and control schemes to future work.

\section{Experimental setup}

All the welding experiments were bead-on-plate welds in the commonly used aluminium alloy AA 6082-T6. The standard specimens were $3 \mathrm{~mm}$ thick, $700 \mathrm{~mm}$ long and $100 \mathrm{~mm}$ wide. To test the controller, some plates were water-cut into special shapes as shown in Figs. 2 and 5. Narrowed zones cause a reduction of the heat dissipation and, accordingly, an increasing welding temperature for uncontrolled welds (i.e. with constant welding speed). The different geometries are welded with and without temperature controller and compared.

\section{Results}

\subsection{Temperature analysis of the plunge operation}

The TWT method as described in Section 2.2 is one of the few methods that can provide temperature information from the whole plunging operation, i.e. the moment the tool probe touches the surface until the shoulder is in contact. The temperature response is recorded for different plunge force

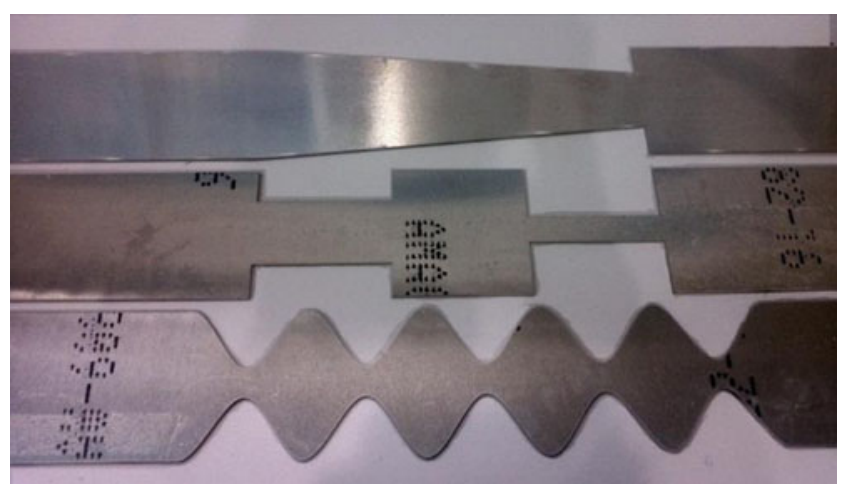

Fig. 5 Different workpiece geometries for testing the temperature controller (referred to as linear, step and sinusoidal shape) 
settings, from 3,000 to $9,000 \mathrm{~N}$, each with a low and high spindle speed ( 800 and $1,500 \mathrm{rpm})$. The time to reach the set plunge temperature of $390^{\circ} \mathrm{C}$, the "plunge time", is measured for each parameter set as shown in Fig. 6. The fastest plunge operation takes $1.7 \mathrm{~s}$ at $9,000 \mathrm{~N}$ and 1,500 rpm.

Two temperature recordings are analysed in detail (Fig. 7): one at $6,000 \mathrm{~N}$ (green) and one at 8,000 $\mathrm{N}$ of axial force (blue), both with a $1,500-\mathrm{rpm}$ spindle speed. When the probe comes in contact with the material, the contact area is small, and accordingly, the heat generation is low. When the shoulder comes in contact with the workpiece, the TWT temperature is $320^{\circ} \mathrm{C}$ for the 6,000 -N weld (Fig. 8(B)). The temperature of the $8,000-\mathrm{N}$ weld is about $50^{\circ} \mathrm{C}$ less (Fig. 7(A)). The material in the latter is less softened, and the workpiece shows more mechanical deformation with this more "aggressive" plunge force.

A temperature dip is observed when the cold shoulder touches the workpiece material. This is due to the type of temperature measurement method, which measures a temperature close to the lowest temperature at the tool-workpiece interface. The heat generation rate increases significantly once the shoulder is in contact, due to the larger contact area, and the temperature increases quickly. The transition from plunge to welding movement is triggered automatically through the temperature controller. As soon as the desired plunge temperature is reached, the controller will send a command to the robot to initiate the actual welding operation. Once the robot starts the forward welding movement, the temperature stabilises around the set temperature of $420^{\circ} \mathrm{C}$.

The force can be increased even further (above 8,000 N), but this increases the risk of probe fracture, deformation of the workpiece and over-plunging, causing excessive flash (see insert in Fig. 6).

The same experiment is performed on an existing FSW joint line. The pre-welded material has partially lost its hardness that was obtained from the T6 heat treatment. The tool could penetrate easier into the material, and the plunge operation took less time. This also means that, when the tool penetrates or crosses a previously welded joint, there will be a greater risk of a meltdown.

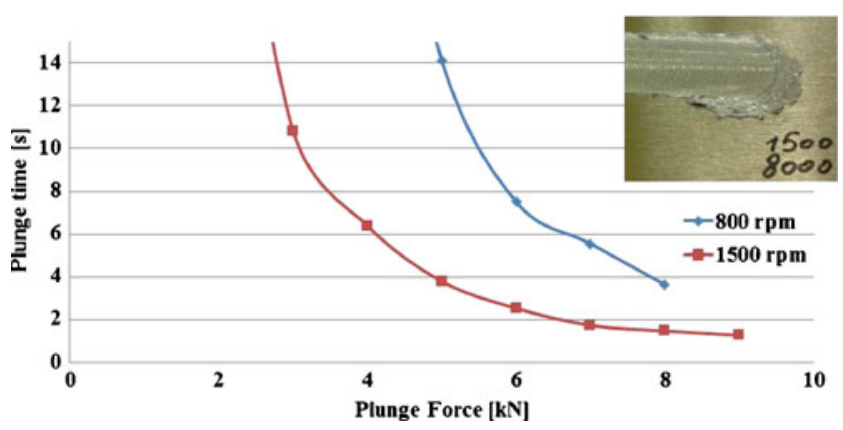

Fig. 6 The plunge time decreases with increasing plunge force. The top right insert shows the excessive flash during plunging with $8,000 \mathrm{~N}$ of force

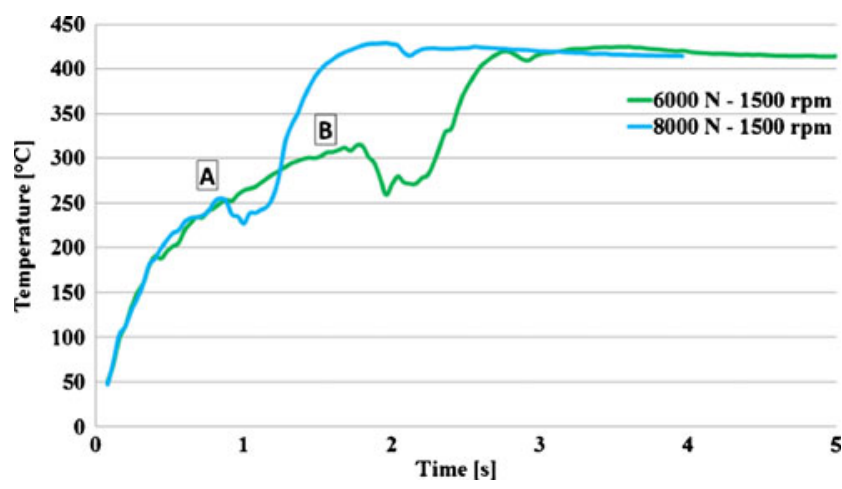

Fig. 7 Plunge time and temperature for two different force parameter settings

\subsection{System identification and controller design}

The temperature and force controllers are considered decoupled. The temperature controller controls the spindle speed and the force controller the axial position. In order to tune the temperature PI controller, a first-order process model was acquired through step responses from a step in spindle speed to measured temperature at a steady-state welding process. The measured disturbance and a first-order approximation are calculated as shown in Fig. 8.

The transfer function $\left(G_{p}\right)$ of the first-order process approximation is deduced from the temperature signal in Fig. 8. The controller will communicate with the robot control system, using the ABB RAPID language. The sampling frequency of the temperature is limited by the iteration speed of the robot program. The loop time for the temperature controller is set to $5 \mathrm{~Hz}$. This is considered the main delay in the process, and therefore the dead time is set equal to one period $(0.2 \mathrm{~s})$ of sampling. ${ }^{1}$ The green curve indicates the approximated process transfer function, according to the following:

$G_{p}(s)=\frac{K_{p}}{1+\tau_{p} s} \cdot e^{-\tau_{d} s}=\frac{3.84}{1+0.85 \mathrm{~s}} \cdot e^{-0.2 s}$

with $\left[K_{p}\right]=\frac{{ }^{\circ} \mathrm{C}}{s}$ and $[\tau]=s$. The controller is optimised using the Bode diagram technique and following a common PI-tuning method [19]. The optimisation is made in MATLAB Control System Toolbox, and the non-linear dead time is approximated using a Padé approximation. The controller formulation is according to the following:

$G_{P I}=K_{i} \cdot \frac{1+T_{i} s}{s}$

\footnotetext{
${ }^{1}$ Outside the equations, seconds are abbreviated "s". Within the equations, the letter "s" refers to the parameter of the Laplace transformation.
} 


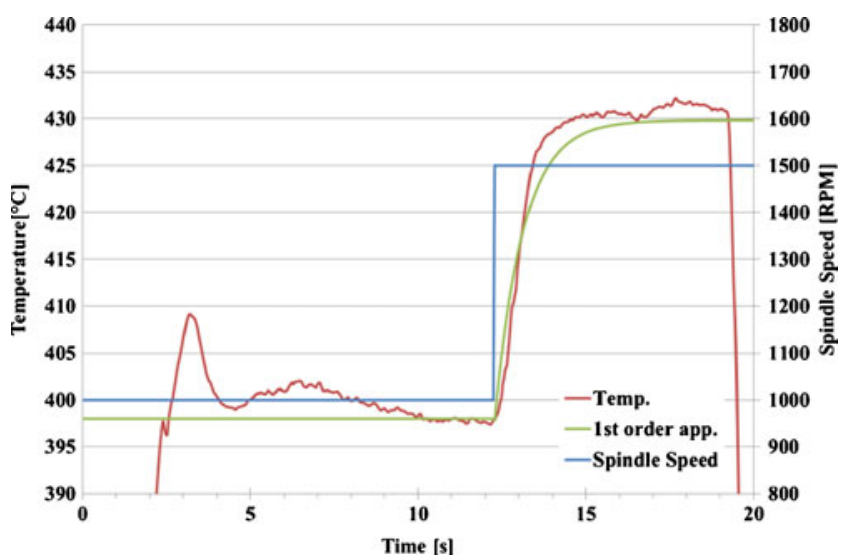

Fig. 8 Response of the temperature to a spindle speed step variation from 1,000 to $1,500 \mathrm{rpm}$

The phase angle of the controller at the cross-over frequency can be written as follows:

$\angle G_{P I}\left(j \omega_{c}\right)=180^{\circ}+\phi_{m}-\angle G_{p}\left(j \omega_{c}\right)$

With the chosen optimisation criterion, the phase margin $\phi_{m}$ is chosen to $45^{\circ}$, and the cross-over frequency is chosen to $\omega_{c}=0.41 \cdot \omega_{G 150}$, where $\omega_{\mathrm{G} 150}$ is the frequency corresponding to a phase angle of the transfer function of $-150^{\circ}$. The PIcontroller parameters can then be calculated as follows:

$$
\begin{aligned}
& T_{i}=\frac{1}{\omega_{c} \cdot \tan \left(-\angle G_{P I}\left(j \omega_{c}\right)\right)}=0.47 \\
& K_{i}=\frac{\omega_{c}}{\mid G\left(j \omega_{c} \mid \cdot \sqrt{1+\left(\omega_{c} \cdot T_{i}\right)^{2}}\right.}=60.6
\end{aligned}
$$

Once the controller parameters are identified, the PIcontroller transfer function can be written as follows:

$$
G_{P I}(s)=K_{i} \cdot\left(\frac{1+\mathrm{T}_{\mathrm{i}} s}{s}\right)=60.6 \cdot\left(\frac{1+0.47 s}{s}\right)
$$

This transfer function is used, in the above notation, as PI controller in the LabVIEW software.

\subsection{Comparison of the TWT and type K thermocouples}

In an attempt to compare the TWT measurements with standardised thermocouples, small holes were drilled in a 3$\mathrm{mm}$ aluminium workpiece along the joint line. Thermocouples were inserted from the bottom of the plate. Two weld runs were made along the joint line to cut off the tops of the thermocouples and to bring the material to a post-welded state, i.e. reducing the effect of the T6 hardening. This caused that the following runs over the same plate were measured in the same location and with very similar material properties, which makes them comparable. Then six samples with three different rotational speeds were welded and compared to the TWT measurements. The three set TWT temperatures $(370,390$ and $410{ }^{\circ} \mathrm{C}$ ) are compared to the corresponding peak temperatures at the thermocouples. The results are shown in Fig. 9.

The temperatures measured by thermocouples TC 2 , TC 3 and TC 4 are equal within a tolerance of $5{ }^{\circ} \mathrm{C}$; only TC 1 shows lower values but is consistent with the others. This is caused by the slight off-centre positioning of the thermocouple TC 1.

The TWT measurements correspond to the temperature close to the edge of tool shoulder, while the thermocouples correspond to the temperature at the tip of the tool probe. Therefore, the values of the measurements should not be compared directly, but temperature differences from the set point are considered instead. The peak temperatures at TC 2 are chosen for comparison with the TWT.

The peak temperatures, measured by TC 2 are 342,375 and $415^{\circ} \mathrm{C}$ for the three set points. This means that a change in the set point of the controller by $20^{\circ}$ will cause a significantly higher difference at the tip of the probe. Despite the smaller TWT temperature changes, the measurement method behaves in a similar way as the thermocouple measured temperature and is considered to be suitable for control purpose.

\subsection{Testing the controller performance}

To simulate a disturbance in the heat distribution, a plate was manufactured where the width decreased from 100 to $20 \mathrm{~mm}$ (step-shaped plate in Fig. 5). The heat dissipation is limited in the narrow zone, causing the temperature to increase. The welds with and without controller are shown in Fig. 10.

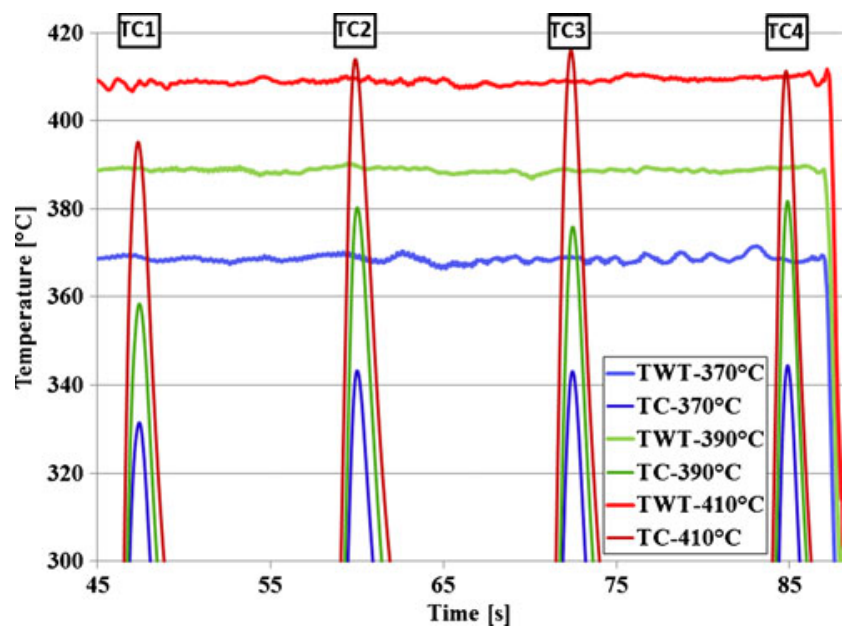

Fig. 9 Temperature measurements of the four thermocouples inside the workpiece (single spot measurement) and the TWT method (continuous measurement) 


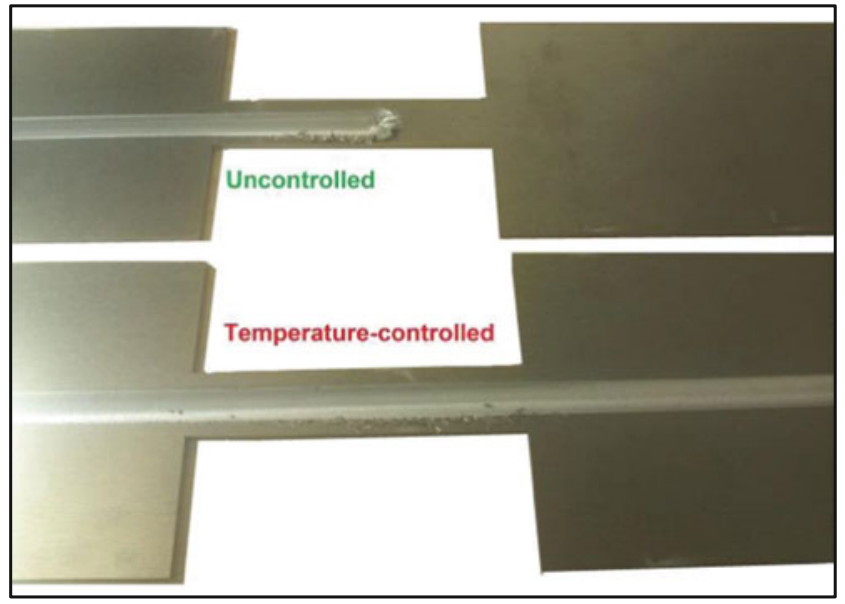

Fig. 10 The step-shaped workpieces. Uncontrolled welding results in a meltdown of the tool. With the temperature controller enabled, the narrow zone is successfully passed

The temperature measurements shown in Fig. 11 correspond to the welds in Fig. 10 with (red) and without (green) temperature controller.

During the uncompensated weld, the process stabilised at $424{ }^{\circ} \mathrm{C}$ in the standard plate width. The temperature quickly increased when the tool approaches the narrow zone and the tool started to melt down into the material around $433^{\circ} \mathrm{C}$. The process had to be aborted at $443{ }^{\circ} \mathrm{C}$, after $55 \mathrm{~s}$, to prevent a further meltdown.

The temperature of the controlled weld was deliberately set to create a "hot weld", just below the critical temperature, i.e. to $432{ }^{\circ} \mathrm{C}$, to prove the precision of the controller. The controller successfully passed the narrow zone, with a slight increase in flash formation in the narrow zone.

The controller was also tested on a sinusoidally shaped workpiece, causing constantly varying heat dissipation in the

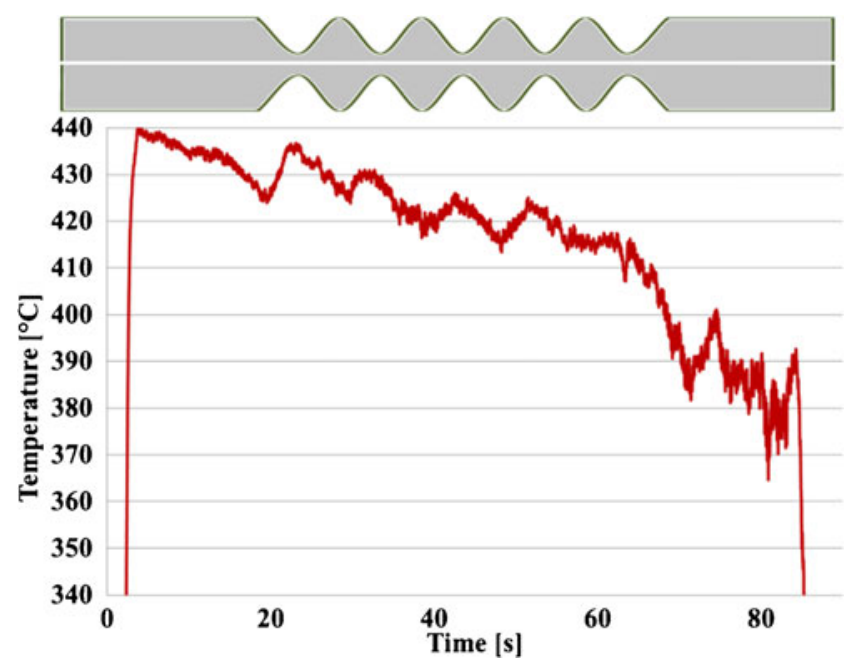

Fig. 12 Temperature signal for the sinusoidal shaped workpiece without controller. The geometrical shape of the workpiece (top) is mapped with the time plot to indicate the locations corresponding to the temperature peaks

material and thus influencing the temperature. The uncontrolled weld (Fig. 12) showed temperature increases of around $10{ }^{\circ} \mathrm{C}$ for each narrow passing. With the controller enabled, the spindle speed decreased with up to $150 \mathrm{rpm}$ in the narrow passing, in order to maintain a constant temperature (Fig. 13).

\section{Discussion}

The adopted TWT temperature measurement method is easy to implement and shows accurate temperature measurements. These can be used for controlling the plunge operation, controlling the welding operation or just supervision during welding. The plunge time can be significantly reduced by applying a higher tool force and to a lesser extent by increasing the rotational speed. The required plunge force for a
Fig. 11 Temperature signal for the step-shaped workpiece with and without controller. The blue graph shows the spindle speed for the controlled weld

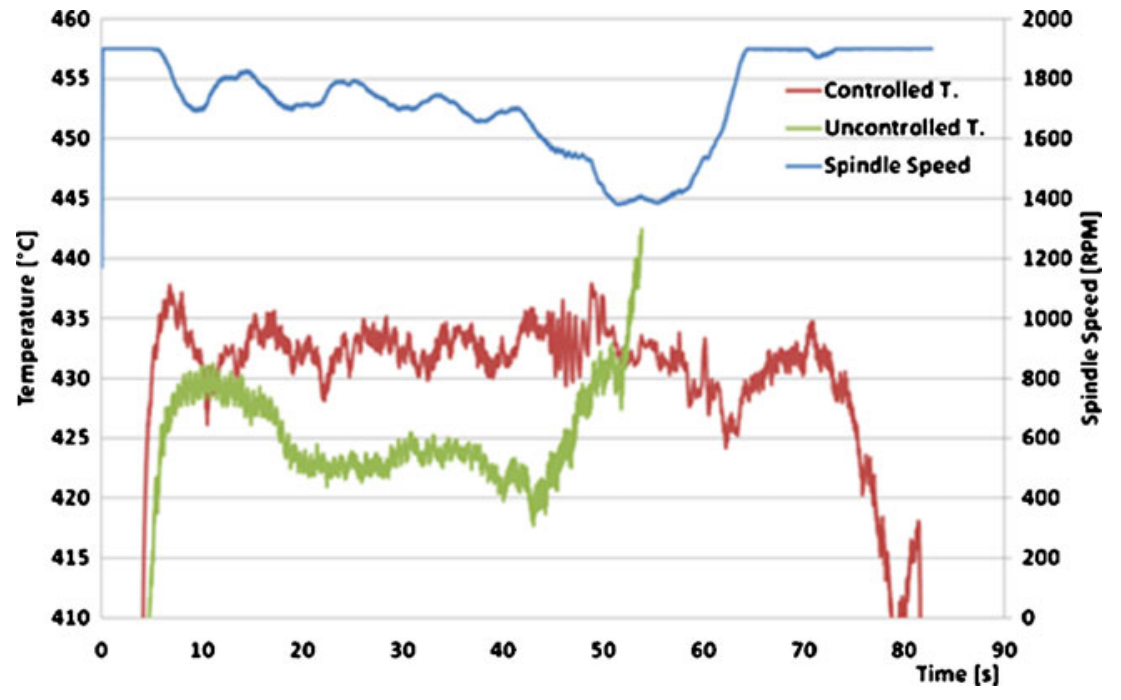




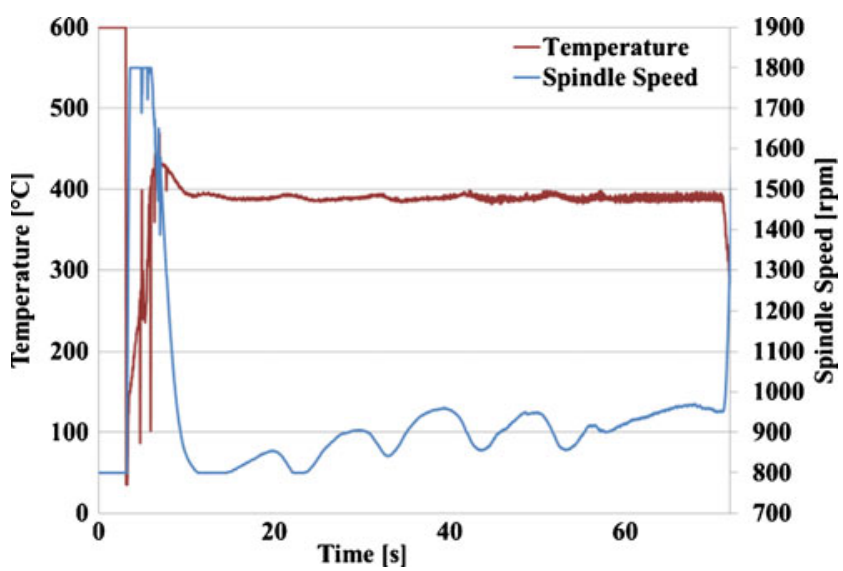

Fig. 13 The controlled spindle speed and the resulting welding temperature for the sinusoidal shaped workpiece

certain material is mainly depending on the material hardness, which relates to the basic definition of hardness - "the resistance of a material to plastic deformation, due to a load from a sharp object" [20] —in this case, the FSW tool.

Although the plunge time could be reduced significantly when the force was increased to $9,000 \mathrm{~N}$, this could not be desirable in a production environment for different reasons: The weld might be applied on thin walls or close to an edge, which could damage or deform the complete product. A high plunge force will also reduce the tool life. Only for many short welds that optimisation of the plunge speed could be beneficial.

The transition from plunging to welding was previously based on the tool position, using a plunge depth parameter. This parameter is, however, hard to identify due to robot deflections, which are depending on the force and the position and orientation in the robot's workspace. Given products with complex geometries, this can result in a trial-and-error approach. With the temperature-based method presented in this
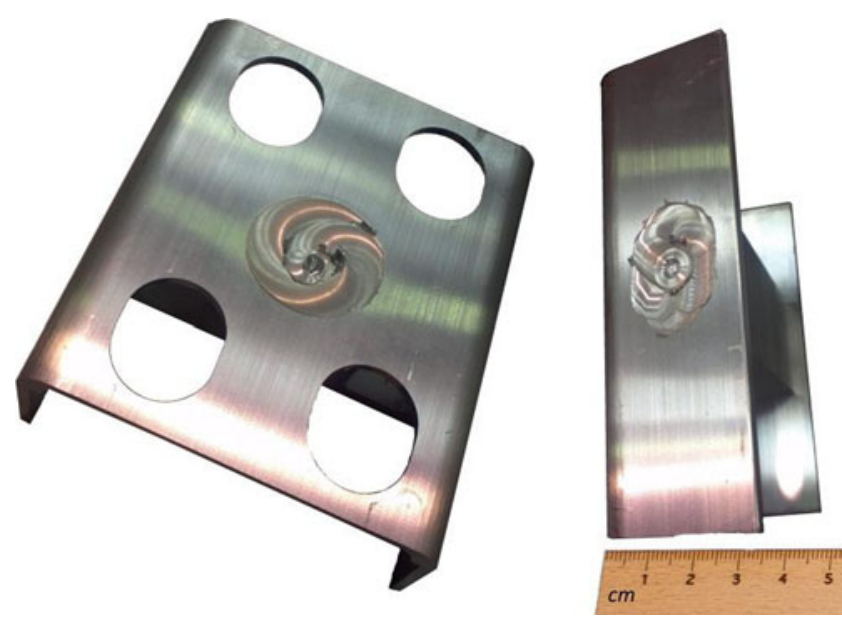

Fig. 14 Industrial application of robotic FSW. The temperature controller can reduce programming time and increase the robustness of the process. CSAPA

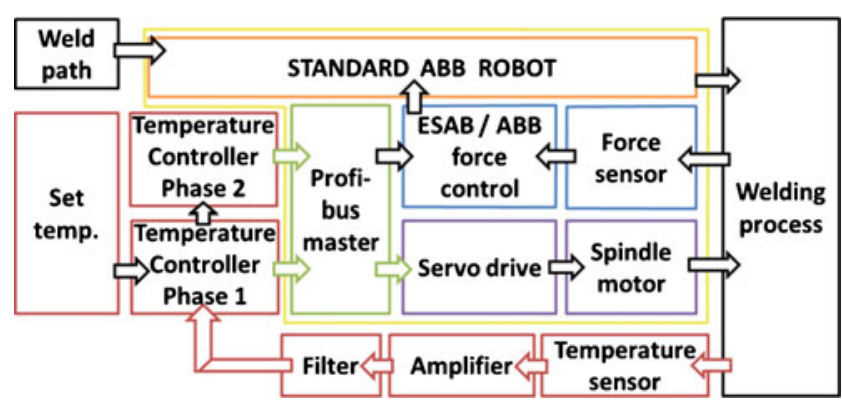

Fig. 15 Control scheme for robotic FSW with both spindle speed and axial force parameter modification

work, the plunge temperature can be equal to the chosen welding temperature and is independent of location, force or workpiece geometry. Furthermore, it makes the dwell time parameter obsolete as the plunge operation continues until the desired temperature is reached.

Industrial applications such as the product in Fig. 14 can benefit from the presented controller in different ways: The programming time can be reduced because the spindle speed changes continuously and does not need to be programmed between each move instruction of the robot path. The process also becomes less sensitive to variations in material thickness. Furthermore, if the ambient conditions change (e.g. due to cold tools and fixtures after production stops), the controller will automatically increase the spindle speed to adapt to these variations.

\section{Conclusions}

Temperature feedback from the novel TWT measurement method is used for controlling different aspects of the FSW process, during the plunging and the welding operation.

A temperature controller is successfully implemented on a force-controlled FSW robot. The spindle speed is used as control parameter for a PI controller.

Non-constant heat dissipation is obtained by welding different workpiece geometries. The controller is able to maintain a constant temperature within $10{ }^{\circ} \mathrm{C}$ of the requested temperature. The temperature profile during plunging is analysed, and the plunge time is measured for different parameters. Increasing the plunge force can significantly reduce the plunge time, but also causes a lower temperature when the tool shoulder hits the workpiece. This results in more deformation of the workpiece. The transition from plunging to welding movement is initiated when the measured temperature reaches the chosen welding temperature.

The temperature controller allowed welding of workpiece with highly varying geometries and narrow sections with a width of only twice the shoulder diameter. 
The temperature differences, measured with the presented TWT method correspond well with thermocouple measurements but are consistently smaller. This is, however, not a problem for maintaining a stable process with constant temperature, which was the aim of the conducted research.

The presented process model and temperature controller were shown to be accurate enough for the performed experiments. As complexity of the weld path and welding speeds increase, there might be a need for a higher-order process approximation and a different controller type. These limitations of the controller are subject to further study.

The presented work uses the spindle speed as parameter to control the heat input during FSW. There are, however, limits to the maximal and minimal rpm to guarantee a successful weld. A strategy to allow more flexibility in the parameter settings is shown in Fig. 15. The operator decides the boundaries of the spindle speed and a suitable axial force. If the controller output approaches the lower boundary of the process window (in the experiment of Fig. 13, the lower boundary is set to $800 \mathrm{rpm}$ ), another parameter will be modifiedthe axial force. This will be introduced as the phase 2 controller. The axial force will be reduced when the temperature is too high at the lower rpm limit and increased when the temperature is too low at the upper rpm limit. This is not a full cascade controller as there is no closed-loop force feedback to the temperature controller. From a production perspective, this strategy is beneficial as it does not require an operator who is highly experienced with the FSW process to create a working set of parameters. Furthermore, it could significantly reduce the time to find optimal FSW parameters for a specific application.

In order to increase the system performance, the spindle speed could be sent directly to the servo drive, avoiding data forwarding through ABB's RAPID programming language.

Similar temperature measurement systems for classic FSW machines have been developed, as described in Section 1. Experiments with the same FSW tools and parameters on the same specimens could provide a better understanding on how these temperature measurements relate to, e.g. thermocouple measurements.

Acknowledgments The authors gratefully acknowledge the support from the Knowledge Foundation of Sweden in the framework of the ARoStir research project and the industrial partners SAPA and ESAB.

Open Access This article is distributed under the terms of the Creative Commons Attribution License which permits any use, distribution, and reproduction in any medium, provided the original author(s) and the source are credited.

\section{References}

1. Thomas WM, Nicholas ED, Needham JC, Murch MG, Temple-Smith P, Dawes CJ (1991) Friction stir butt welding. GB Patent No. 9125978.8, International patent application No. PCT/ GB92/02203

2. Lienert TJ, Stellwag WL, Grimmett BB, Warke RW (2003) Friction stir welding studies on mild steel. Weld J 82:1-9

3. Sato YS, Arkom P, Kokawa H, Nelson TW, Steel RJ (2008) Effect of microstructure on properties of friction stir welded Inconel Alloy 600. Mater Sci Eng, A 477(1-2):250-258. doi:10.1016/j.msea. 2007.07.002

4. Cater S, Martin J, Galloway A, McPherson N (2013) Comparison between friction stir and submerged arc welding applied to joining DH36 and E36 shipbuilding steel. Friction Stir Welding and Processing VII. doi:10.1002/9781118658345.ch6

5. De Backer J, Christiansson AK, Oqueka JM, Bolmsjö G (2012) Investigation of path compensation methods for robotic friction stir welding. Industrial Robot: An International Journal 39(6):601-608. doi:10.1108/01439911211268813

6. Cook GE, Crawford R, Clark DE, Strauss AM (2004) Robotic friction stir welding. Industrial Robot: An International Journal 31(1):55-63 doi:10.1108/01439910410512000

7. Soron M (2007) Robot system for flexible 3D friction stir welding. Örebro University, Örebro

8. Smith C (2000) Friction stir welding using a standard industrial robot. In: 2nd International friction stir welding symposium, Gothenburg, Sweden,

9. Von Strombeck A, Schilling C, Dos Santos JF (2000) Robotic friction stir welding - tool technology and applications. In: 2nd International friction stir welding symposium, Gothenburg, Sweden, TWI

10. Shi J, Wang Y, Zhang G, Ding H (2013) Optimal design of 3DOF PKM module for friction stir welding. Int J Adv Manuf Technol 66(9-12):1879-1889 doi:10.1007/s00170-012-4467-7

11. Longhurst W, Strauss A, Cook G, Fleming P (2010) Torque control of friction stir welding for manufacturing and automation. Int J Adv Manuf Technol 51(9):905-913. doi:10.1007/s00170-010-2678-3

12. Davis TA, Ngo PD, Shin YC (2012) Multi-level fuzzy control of friction stir welding power. Int J Adv Manuf Technol 59(5-8):559 567. doi:10.1007/s00170-011-3522-0

13. Chao YJ, Qi X, Tang W (2003) Heat transfer in friction stir welding-experimental and numerical studies. J Manuf Sci Eng 125(1):138-145 doi:10.1115/1.1537741

14. Schmidt H, Hattel J (2005) Modelling heat flow around tool probe in friction stir welding. Science and Technology of Welding and Joining 10(2):176-186. doi:10.1179/174329305x36070

15. Cederqvist L, Garpinger O, Hägglund T, Robertsson A (2012) Cascade control of the friction stir welding process to seal canisters for spent nuclear fuel. Control Eng Pract 20(1):35-48. doi:10.1016/j. conengprac.2011.08.009

16. Smith C, Schroeder K (2012) An automated path planning and programming system with real-time adaptive control for friction stir processing of cast surfaces. In: 9th international friction stir welding symposium, Huntsville (AL), USA

17. Fehrenbacher A, Duffie NA, Ferrier NJ, Pfefferkorn FE, Zinn MR (2011) Toward automation of friction stir welding through temperature measurement and closed-loop control. J Manuf Sci Eng 133(5): 051008. doi:10.1115/1.4005034

18. De Backer J, Bolmsjö G (2013) Thermoelectric method for temperature measurement in friction stir welding. Science and Technology of Welding and Joining. doi:10.1179/1362171813Y.0000000135

19. Lennartson B (2002) Reglerteknikens grunder. Studentlitteratur, Lund

20. Martin PM (2011) Introduction to surface engineering and functionally engineered materials. Scrivener, Hoboken 